\title{
Uso de uma Espátula de Ayre Modificada para Colheita Colpocitológica
}

\author{
Use of a Modified Ayre Spatula in Cervical Cytology
}

Álvaro Luiz Lage Alves ${ }^{1}$, Geraldo Magela de Almeida², Victor Hugo de Melo ${ }^{3}$

\section{RESUM0}

Objetivos: os autores modificaram a espátula de Ayre original visando otimizar a colheita endocervical. $O$ estudo verificou se a capacidade da espátula modificada em colher células da endocérvice é semelhante à obtida pela combinação espátula de Ayre-escova e melhor do que a da espátula de Ayre isoladamente.

Métodos: foi realizado um estudo diagnóstico e simples cego. As pacientes foram distribuidos aleatoriamente em três grupos de coleta (espátula de Ayre, combinação espátula de Ayreescova e espátula modificada). Após exclusão dos dados de 25 pacientes, foram avaliados 276 esfregaços com atenção quanto à presença de células escamosas, metaplásicas, endocervicais colunares e suas combinações. Para comparação dos métodos, foram utilizados $o$ teste do $\chi^{2}$ com valores de Yates corrigido e o teste exato de Fisher.

Resultados: a combinação espátula de Ayre-escova apresentou o melhor desempenho na produção de células endocervicais colunares. Quando comparada à combinação espátula de Ayre-escova, a espátula modificada produziu menor sangramento nos esfregaços $\left(\chi^{2}=\right.$ $7,98 ; p=0,004)$ e não foi estatisticamente inferior na obtenção de células metaplásicas $\left(\chi^{2}=\right.$ 2,97; $p=0,08$ ). Quando comparada com a espátula de Ayre, foi estatisticamente superior na obtenção de células endocervicais colunares $\left(\chi^{2}=21,37 ; p=0,000004\right)$ e apresentou um maior percentual de esfregaços apresentando células escamosas acompanhadas de células metaplásicas e/ou endocervicais colunares $\left(\chi^{2}=10,97 ; p=0,0009\right)$.

Conclusão: a espátula modificada melhorou a qualidade da amostra obtida em relação a que se obtém unicamente com a espátula de Ayre, podendo ser utilizada em populações nas quais o uso da escova for impossivel.

PALAVRAS-CHAVE: Colpocitologia. Colo: câncer. Câncer: rastreamento. Lesões préneoplásicas do colo uterino.

\section{Introdução}

O câncer de colo uterino é o segundo mais comum entre as mulheres no Brasil. No ano de 1998 foi prevista a ocorrência de 21.725 casos

\footnotetext{
1 Departamento de Medicina Social. Faculdade de Ciências Médicas de Minas Gerais (FCMMG).

2 Departamento de Patologia. Faculdade de Ciências Médicas de Minas Gerais (FCMMG).

3 Departamento de Ginecologia e Obstetrícia. Faculdade de Medicina da Universidade Federal de Minas Gerais (FMUFMG). Correspondência:

Álvaro Luiz Lage Alves.

Faculdade de Ciências Médicas de Minas Gerais - Internato Rural.

Alameda Ezequiel Dias, 275 - Centro

30130-110 - Belo Horizonte - Minas Gerais

Fone: (31) 274-5742 - Fax: (31) 222-1324.
}

novos e de 6.815 óbitos no país ${ }^{1}$. O rastreamento de pacientes com lesão intra-epitelial escamosa (LIE) é comprovadamente eficaz quando realizado por meio do raspado ecto e endocervical corado pelo método de Papanicolaou ${ }^{2}$. A qualidade das amostras colpocitológicas influencia diretamente a eficácia do rastreamento. O consenso tem sido considerar como satisfatórios os esfregaços que contenham células escamosas acompanhadas de células metaplásicas e/ou endocervicais colunares, comprovando a realização da colheita na junção escamocolunar e zona de transformação, locais onde com maior freqüência ocorrem as transformações neoplásicas ${ }^{3}$. Os alarmantes indices de resultados falso-negativos e o desenvolvimento de atipias em mulheres cujos 
esfregaços prévios não continham células endocervicais colunares são motivos para a exigência da presença destas células no esfregaço ${ }^{4}$. A qualidade da amostra é também diretamente relacionada com a habilidade e experiência de quem realiza a colheita e com os dispositivos utilizados ${ }^{5}$.

A maioria dos autores afirma que a escova modelo Cytobrush é o melhor dispositivo para amostrar a endocérvice ${ }^{6,7,8,9}$. Afirmam também que a combinação espátula de Ayre-escova é a melhor técnica na realização do raspado ${ }^{6,10}$. O uso isolado da espátula de Ayre tem sido questionado pela sua deficiência em obter células endocervicais colunares. Estudos apontam que a sua utilização é eficaz apenas na amostra ectocervical e desaconselham sua utilização isolada no rastreamento de lesões pré-malignas ${ }^{11,12}$.

No Brasil, a crescente exclusão da população pobre dos cuidados básicos de saúde aliada à progressiva dificuldade de acesso a tecnologias mais qualificadas justifica a tentativa de se desenvolverem técnicas mais simples, baratas e eficazes. Buscando instrumentos que otimizem a colheita endocervical, modificamos a feição original da espátula de Ayre. O objetivo foi idealizar um dispositivo para ser utilizado em populações nas quais a escova não estiver disponivel. Diversas espátulas modificadas já haviam sido elaboradas visando aperfeiçoar a técnica e melhorar a adequação dos esfregaços. Foram criadas a espátula Armovical, de Lerner, Aylesbury, Rocket, Milex, biométrica, a Szalay cyto-spatula, a Multiespátula, o dispositivo Accu-Pap, o Cytopick e o Papaplast, dentre outros. A espátula do presente estudo se distingue das criadas previamente pelo fato de possuir extremidades com funções distintas, sendo uma destinada exclusivamente para a colheita ectocervical e a outra exclusivamente para a endocervical. A extremidade utilizada para colheita endocervical foi uma adaptação da extremidade arredondada da espátula de Ayre. Ela apresenta um prolongamento central em relação à haste e este aspecto também difere das demais espátulas modificadas (à excessão do Cytopick que é, porém, um instrumento utilizado apenas para colheita endocervical).

\section{Pacientes e Métodos}

A espátula modificada é de madeira e possui comprimento $(18 \mathrm{~cm})$ e uma das extremidades (extremidade em "gancho") idênticos à da espátula de Ayre. A outra extremidade é alongada, afilada, com formato ogival, posição centralizada em relação à haste e mede $2,0 \mathrm{~cm}$ de comprimento e $0,5 \mathrm{~cm}$ de largura na sua porção mais proximal (Figura 1). Ela foi idealizada por um dos autores do presente trabalho e fabricada de forma artesanal por um docente do Colégio Técnico da Universidade Federal de Minas Gerais, UFMG, não estando vinculada a nenhum processo de industrialização ou a fabricantes de instrumentos. A espátula de Ayre e a escova, aqui utilizados, apresentam conformações e medidas tradicionais.

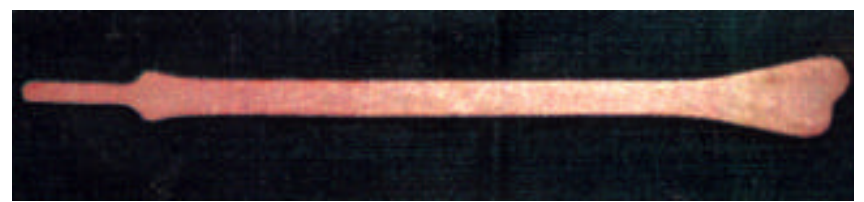

Figura 1 - Espátula de Ayre modificada

O presente trabalho foi autorizado pela Comissão de Ética em Pesquisa da instituição. Foi realizado um estudo diagnóstico, randômico e simples cego, envolvendo três técnicas de colheita. Os esfregaços foram preparados por uma única pessoa, no período de 17 de janeiro de 1997 a 30 de janeiro de 1998. Pacientes alocadas para o Grupo I tiveram seus esfregaços preparados com a espátula de Ayre (rotação da extremidade em "gancho" em $360^{\circ}$ na ectocérvice). No Grupo II, as colheitas foram realizadas primeiro com a espátula de Ayre (extremidade em "gancho") na ectocérvice e em seguida com a escova na endocérvice (ambas com rotação de $360^{\circ}$ ). No Grupo III, as colheitas foram realizadas primeiro na ectocérvice, utilizando a extremidade em "gancho" da espátula modificada, e a seguir na endocérvice, utilizando sua extremidade afilada (ambas com rotação de $360^{\circ}$ ). O material foi espalhado uniformemente em lâmina de vidro única, utilizando-se ambos os lados dos dispositivos.

Foram incluídas na análise 276 mulheres no menacme e com o colo uterino intacto. Os dados de 25 mulheres foram excluidos da análise. Os motivos das exclusões foram amenorréia, gravidez, puerpério, lactação e história de conização ou cauterização cérvico-uterina. Outros motivos de exclusão foram utilização de medicação intravaginal, duchas ou coito previamente ao dia da coleta e presença de leucorréia abundante e/ou sangramento no momento do exame especular.

Os 276 esfregaços foram examinados por um único citopatologista, com atenção quanto à presença de células escamosas, metaplásicas, endocervicais colunares e suas combinações.

Foi criada uma metodologia para avaliação quantitativa das células escamosas, metaplásicas, endocervicais colunares e do sangramento, que 
adotou, simultaneamente, critérios utilizados por diversos autores. Foram considerados satisfatórios aqueles esfregaços contendo mais de 200 células escamosas, mais de 10 células metaplásicas e mais de 20 células endocervicais colunares ${ }^{7,13}$. O grau de sangramento também foi avaliado e quantificado (nenhum, pouco, moderado e abundante) ${ }^{8,10}$. Esfregaços contendo quantidade excessiva de sangue e/ou material purulento e aqueles com material insuficiente para avaliação foram excluídos da análise ${ }^{9}$.

Os dados foram inseridos no Programa Epi Info, versões 5.01b e 6.04b. Para comparação dos métodos, utilizaram-se o teste do $\chi^{2}$ com valores de Yates corrigido e o teste exato de Fisher.

\section{Resultados}

As 276 mulheres se encontravam no menacme. A idade delas variou de 17 a 52 anos, com média de 32,3 . Duzentas e cinquenta e seis $(92,8 \%)$ já haviam engravidado e 250 (90,6\%) já haviam tido partos.

Noventa e seis esfregaços $(34,8 \%)$ foram preparados apenas com a espátula de Ayre (Grupo I), $90(32,6 \%)$ com a combinação espátula de Ayreescova (Grupo II) e 90 (32,6\%) com a espátula modificada (Grupo III).

Não houve esfregaços classificados como insatisfatórios. Foram diagnosticadas dez LIE de baixo grau (3 pela espátula de Ayre, 5 pela combinação espátula de Ayre-escova e 2 pela espátula modificada) e 2 LIE de alto grau (ambas pela espátula modificada). O desempenho dos três métodos na obtenção de células escamosas, metaplásicas, endocervicais colunares e suas combinações se encontra na Tabela 1.

Tabela 1 - Distribuição dos esfregaços preparados com os três métodos quanto à obtenção de células escamosas, metaplásicas, endocervicais colunares e suas combinações.

\begin{tabular}{lccc}
\hline Esfregaços & $\begin{array}{c}\text { Espátula de } \\
\text { Ayre }\end{array}$ & $\begin{array}{c}\text { Combinação espátula } \\
\text { de Ayre-escova }\end{array}$ & $\begin{array}{c}\text { Espátula } \\
\text { modificada }\end{array}$ \\
\hline$>200$ células escamosas & $96(100,0 \%)$ & $90(100,0 \%)$ & $90(100,0 \%)$ \\
$>10$ células metaplásicas & $65(67,7 \%)$ & $82(91,1 \%)$ & $73(81,1 \%)$ \\
$>20$ células colunares & $37(38,5 \%)$ & $84(93,3 \%)$ & $66(73,3 \%)$ \\
$>10$ células metaplásicas, porém <20 colunares & $31(32,3 \%)$ & $6(6,7 \%)$ & $16(17,8 \%)$ \\
$>20$ células colunares, porém <10 metaplásicas & $3(3,1 \%)$ & $8(8,9 \%)$ & $9(10,0 \%)$ \\
Com células escamosas, metaplásicas e colunares & $34(35,4 \%)$ & $76(84,4 \%)$ & $57(63,3 \%)$ \\
Com células escamosas, metaplásicas e/ou colunares & $68(70,8 \%)$ & $90(100,0 \%)$ & $82(91,1 \%)$ \\
Com células escamosas apenas & $28(29,2 \%)$ & 0 & $8(8,9 \%)$ \\
\hline
\end{tabular}

Não houve diferença entre os métodos com relação à obtenção de células escamosas. Com relação à obtenção de células metaplásicas, não houve diferenças estatisticamente significativas entre a espátula modificada e a espátula de Ayre $\left(\chi^{2}=3,69 ; p=0,05\right)$ e entre a espátula modificada e a combinação espátula de Ayre-escova $\left(\chi^{2}=2,97\right.$; $\mathrm{p}=0,08)$.

Quanto à obtenção de células endocervicais colunares, a espátula modificada foi estatisticamente inferior à combinação espátula de Ayreescova $\left(\chi^{2}=11,56 ; p=0,0007\right)$, porém foi superior à espátula de Ayre $\left(\chi^{2}=21,37 ; \mathrm{p}=0,000004\right)$.

Quanto à proporção de esfregaços apresentando células escamosas acompanhadas de células metaplásicas e/ou endocervicais colunares, a espátula modificada foi inferior à combinação espátula de Ayre-escova ( $p=0,007$, teste exato de Fisher), porém superior à espátula de Ayre $\left(\chi^{2}=\right.$
10,97; $\mathrm{p}=0,0009)$

Com relação à proporção de esfregaços apresentando, simultaneamente, células escamosas, endocervicais colunares e metaplásicas, a espátula modificada apresentou desempenho inferior à combinação espátula de Ayre-escova $\left(\chi^{2}\right.$ $=9,33 ; \mathrm{p}=0,002)$, porém superior à espátula de Ayre $\left(\chi^{2}=13,39 ; p=0,0003\right)$.

A distribuição dos esfregaços preparados pelos três métodos quanto à presença e grau de sangramento se encontra na Tabela 2 . Toda diferença existente entre os métodos com relação ao sangramento ocorreu em decorrência da comparação entre a ausência ou a presença deste, não importando o seu grau. A espátula modificada produziu sangramento estatisticamente inferior à combinação espátula de Ayre-escova $\left(\chi^{2}=7,98\right.$; $\mathrm{p}=0,004)$, porém superior ao da espátula de Ayre $\left(\chi^{2}=10,49 ; p=0,001\right)$. 
Tabela 2 - Distribuição dos esfregaços preparados com os três métodos quanto à presença e grau de sangramento.

\begin{tabular}{lccc}
\hline Grau & $\begin{array}{c}\text { Espátula } \\
\text { de Ayre }\end{array}$ & $\begin{array}{c}\text { Combinação } \\
\text { espátula de } \\
\text { Ayre-escova }\end{array}$ & $\begin{array}{c}\text { Espátula } \\
\text { modificada }\end{array}$ \\
\hline Ausente & $49(51,0 \%)$ & $10(11,1 \%)$ & $27(27,8 \%)$ \\
Pouco & $24(25,0 \%)$ & $38(42,2 \%)$ & $21(23,3 \%)$ \\
Moderado & $15(15,6 \%)$ & $34(37,8 \%)$ & $34(37,8 \%)$ \\
Abundante & $8(8,3 \%)$ & $8(8,9 \%)$ & $10(11,1 \%)$ \\
Total & $96(100,0 \%)$ & $90(100,0 \%)$ & $90(100,0 \%)$ \\
\hline
\end{tabular}

\section{Discussão}

A presente espátula modificada foi idealizada a partir da própria espátula de Ayre e possui a peculiaridade de apresentar extremidades com funções distintas no momento da coleta.

Nesta pesquisa, para a coleta do material nos Grupos II e III efetuamos o raspado ectocervical antes do endocervical. Nossa intenção foi evitar o excesso de sangue presente nos esfregaços quando se realiza a colheita em seqüência inversa ${ }^{14}$. O preparo dos esfregaços em lâmina única se baseou na afirmativa de que este método é tão eficaz quanto o método de dupla lâmina e possui a vantagem de reduzir os custos e o tempo de trabalho no laboratório ${ }^{15}$.

Não comparamos a capacidade dos dispositivos para detecção de atipias, pois além do pequeno tamanho da amostra, as pacientes examinadas não possuíam esfregaços prévios sabidamente anormais. Nenhuma espátula modificada quebrou no momento da coleta ou durante a transferência do material para as lâminas.

Com relação à qualidade da amostra, os resultados da pesquisa confirmaram os achados de diversos outros estudos, ou seja, a combinação espátula de Ayre-escova é realmente a melhor técnica, propiciando a obtenção de um apreciável número de células da endocérvice ${ }^{6,10}$. Acreditamos que dificilmente algum outro dispositivo fornecerá melhor quantidade e qualidade de células endocervicais colunares do que a escova (modelo Cytobrush). Suas cerdas são de nylon e extremamente maleáveis, penetram profundamente nas criptas endocervicais e desprendem um grande número de células bem preservadas.

O estudo também corroborou os resultados daqueles que comprovaram a superioridade da combinação espátula-escova, quando defrontada com as espátulas modificadas ${ }^{8,16}$. Corroborou ainda os achados daqueles que demonstraram que a espátula de Ayre, utilizada isoladamente, é um método deficiente na produção de esfregaços satisfatórios ${ }^{11,12}$.

A espátula modificada alcançou o objetivo almejado e o seu desempenho superior ao da espátula de Ayre confirma os achados de diversos outros estudos que compararam outros modelos de espátulas modificadas com a espátula de Ayre $^{12,17,18,19,20,21,22,23}$. Vierhout ${ }^{24}$ havia comentado que, pelo fato de a Multiespátula (um modelo de espátula modificada) possuir orla aguçada, ela produz mais dor e sangramento (no esfregaço) que a espátula de Ayre. Com relação ao sangramento, nosso achado foi semelhante ao deste estudo, porém não obtivemos relato de dor por parte de nenhuma paciente cujo esfregaço foi preparado com nossa espátula modificada.

Buntinx et al. ${ }^{6}$, examinando 39 publicações, concluíram que, em situações nas quais o uso do escova (modelo Cytobrush) for impossivel, tomar esfregaços da endocérvice e da ectocérvice utilizando ambas extremidades de uma espátula é o procedimento mais apropriado. Em uma metaanálise envolvendo 29 estudos e 85.000 pacientes, Buntinx e Brouwers ${ }^{25}$ apoiaram o uso da combinação espátula-escova (modelo Cytobrush), da combinação espátula-"swab" de algodão, da escova Cervex ou de espátulas com ponta estendida na realização do rastreamento do câncer cervical.

Concluímos que a espátula modificada melhorou a qualidade da amostra em comparação com a obtida unicamente com a espátula de Ayre, podendo ser indicada para o rastreamento do câncer de colo uterino em populações onde o uso da escova for impossivel. Podemos estimar que o seu custo seja bem próximo ao da espátula de Ayre (cem unidades a aproximadamente R\$ 1,35). Sendo assim, comparados ao uso da escova (1 unidade a aproximadamente $R \$ 0,50)$, os custos de sua aplicação seriam vantajosos. Ao utilizá-la, recomendamos a realização da colheita primeiro na ectocérvice e em seguida na endocérvice, a fim de evitar o excesso de sangue na amostra. Para evitar o ressecamento do esfregaço, sugerimos espalhar os materiais colhidos (em lâmina única) somente após efetuadas as duas colheitas.

\section{SUMMARY}

Purpose: the authors modified the original Ayre spatula aiming at optimizing endocervical collection. The study verified if the capacity of the modified spatula in collecting endocervical 
cells is similar to that obtained by the combination brushAyre spatula and better than the Ayre spatula alone.

Methods: a diagnostic and single-blind simple study was performed. The patients were randomly assigned to one of three collection groups (Ayre spatula, combination of brush-Ayre spatula and modified spatula). After excluding data of 25 patients, 276 smears were evaluated with attention to the presence of squamous, metaplastic, and columnar endocervical cells and their combination. In order to compare methods, the $\chi^{2}$ test with corrected Yates values and the exact Fisher test were used.

Results: the combination brush-Ayre spatula presented the best performance in the production of columnar endocervical cells. When compared to the combination of brush-Ayre spatula, the modified spatula produced less bleeding in the smears $\left(\chi^{2}=7.98 ; p=0.004\right)$ and it was not statistically inferior in obtaining metaplastic cells $\left(\chi^{2}=2.97 ; p=0.08\right)$. When compared to the Ayre spatula, it was statistically superior in obtaining columnar endocervical cells $\left(\chi^{2}=21.37\right.$; $p=0.000004)$ and presented a greater percentage of smears presenting squamous cells accompanied by metaplastic and/or columnar endocervical cells $\left(\chi^{2}=10.97 ; p=0.0009\right)$. Conclusions: it was concluded that the modified spatula improved the quality of the sample obtained with the Ayre spatula alone, being able to be used in populations where the use of the brush was impossible.

KEY WORDS: Colpocytology. Collecting devices. Preneoplastic lesions of the uterine cervix.

\section{Referências}

1 - Instituto Nacional do Câncer. Estimativa da incidência e mortalidade por câncer no Brasil, 1998. Rio de Janeiro; 1998.

2 - Van der Graaf Y, Zielhuis GA, Vooijs GP. Cervical cancer mortality in the Netherlands. Int J Epidemiol 1988; 17: $270-6$

3 - Kurman RJ, Solomon D. O sistema Bethesda para o relato de diagnóstico citológico cervicovaginal. Tradução de Dalton de Freitas Santoro; revisão técnica de Carmen Lúcia de Freitas Santoro. Rio de Janeiro: Revinter; 1997.

4 - Elias A, Linthorst G, Bekker B, Vooijs PG. The significance of endocervical cells in the diagnosis of cervical epithelial changes. Acta Cytol 1983; 27: 2259.

5 - Vooijs GP, Elias A, Van der Graaf Y, Poelen-van de Berg M. The influence of sample takers on the cellular composition of cervical smears. Acta Cytol 1986; 30: 251-7.

6 - Buntinx F, Knottnerus JA, André J, Crebolder HFJM, Essed GGM. The effect of different sampling devices on the presence of endocervical cells in cervical smears; a systematic literature review. Eur J Cancer Prev 1994; 3: 23-30.
7 - Dotters DJ, Carney CN, Droegemueller W. Nylon brush improves collection of cervical cytologic specimens. Am J Obstet Gynecol 1988; 159: 814-9.

8 - Hjersing M, Holm E, Larsson G. Comparison between cytobrush and papaplast in sampling vaginal smears. Acta Obstet Gynecol Scand 1991; 70: 595-9.

9 - Szarewski A, Cuzick J, Nayagam M, Thin RN. A comparison of four cytological sampling techniques in a genitourinary medicine clinic. Genitourin Med 1990; 66: 439-43.

10 - McCord ML, Stovall TG, Meric JL, Summitt Jr RL, Coleman SA. Cervical cytology: a randomized comparison of four sampling methods. Am J Obstet Gynecol 1992; 166: 1772-9.

11 - Fokke HE, Salvatore CM, Schipper MEI, Bleker OP. The quality of the Pap smear. Eur J Gynaecol Oncol 1992; 13: 445-8.

12 - Rammou-Kinia R, Anagnostopoulou I, Gomousa M. Comparison of spatula and nonspatula methods for cervical sampling. Acta Cytol 1991; 35: 69-75.

13 - Ferenczy A, Robitaille J, Guralnick M, Shatz R. Cervical cytology with the papette sampler. J Reprod Med 1994; 39: 304-10.

14 - Eisenberger D, Hernandez E, Tener T, Atkinson BF. Order of endocervical and ectocervical cytologic sampling and the quality of the Papanicolaou smear. Obstet Gynecol 1997; 90: 755-8.

15 - Saitas VL, Hawthorne C, Cater J, Bibbo M. Singleslide versus double-slide Pap smear: a comparative study. Diagn Cytopathol 1995; 12: 320-2.

16 - Bauman BJ. Use of a cervical brush for Papanicolaou smear collection; a meta analysis. J Nurse-Midwifery 1993; 38: 267-75.

17 - Blenkinsopp WK, Jenkins JL. Cervical smears: choice of spatula is critical. Lancet 1986; 2: 986.

18 - Bounds W, Grubb C, Metaxas N, Vessey, M. A randomized comparative trial of the performance of the Ayre and the Armovical cervical spatulae. Br J Obstet Gynaecol 1976; 83: 981-7.

19 - Goorney BP, Lacey CJN, Sutton J. Ayre versus Aylesbury cervical spatulas. Genitourin Med 1989; 65: $161-2$.

20 - Pistofides GA, Brown ER, Harris VG, Grainger JM, Spring JE, Carr JVL, et al. Detection of abnormal cervical smears; a comparative study. Acta Obstet Gynecol Scand 1988; 67: 153-4.

21 - Shanmurgaratnam K, Sankar K, Wadehra V. Ayre versus Aylesbury cervical spatulas. Genitourin Med 1989; 65: 402 .

22 - Wachtel E, Gordon H. An improved sampling device for cervical cytology. Lancet 1974; 2: 26-7.

23 - Wolfendale MR, Howe-Guest R, Usherwood MM, Draper GJ. Controlled trial of a new cervical spatula. Br Med J 1987; 294: 33-5.

24 - Vierhout ME. The multispatula: a spatula adjustable to the shape of the individual cervix. Eur J Obstet Gynecol Reprod Biol 1987; 26: 343-7.

25 - Buntinx F, Brouwers M. Relation between sampling device and detection of abnormality in cervical smears: a meta-analysis of randomised and quasirandomised studies. Br Med J 1996; 313: 1285-90. 